\title{
Effects of dexamethasone on the Li-pilocarpine model of epilepsy: protection against hippocampal inflammation and astrogliosis
}

Adriana Fernanda K. Vizuete ${ }^{*} \mathbb{D}$, Fernanda Hansen, Elisa Negri, Marina Concli Leite, Diogo Losch de Oliveira and Carlos-Alberto Gonçalves

\begin{abstract}
Background: Temporal lobe epilepsy (TLE) is the most common form of partial epilepsy and is accompanied, in one third of cases, by resistance to antiepileptic drugs (AED). Most AED target neuronal activity modulated by ionic channels, and the steroid sensitivity of these channels has supported the use of corticosteroids as adjunctives to AED. Assuming the importance of astrocytes in neuronal activity, we investigated inflammatory and astroglial markers in the hippocampus, a key structure affected in TLE and in the Li-pilocarpine model of epilepsy.

Methods: Initially, hippocampal slices were obtained from sham rats and rats subjected to the Li-pilocarpine model of epilepsy, at 1, 14, and 56 days after status epilepticus (SE), which correspond to the acute, silent, and chronic phases. Dexamethasone was added to the incubation medium to evaluate the secretion of S100B, an astrocyte-derived protein widely used as a marker of brain injury. In the second set of experiments, we evaluated the in vivo effect of dexamethasone, administrated at 2 days after SE, on hippocampal inflammatory (COX-1/2, PGE2, and cytokines) and astroglial parameters: GFAP, S100B, glutamine synthetase (GS) and water (AQP-4), and $\mathrm{K}^{+}$(Kir 4.1) channels.

Results: Basal S100B secretion and S100B secretion in high- $K^{+}$medium did not differ at 1, 14, and 56 days for the hippocampal slices from epileptic rats, in contrast to sham animal slices, where high- $\mathrm{K}^{+}$medium decreased S100B secretion. Dexamethasone addition to the incubation medium per se induced a decrease in S100B secretion in sham and epileptic rats ( 1 and 56 days after SE induction). Following in vivo dexamethasone administration, inflammatory improvements were observed, astrogliosis was prevented (based on GFAP and S100B content), and astroglial dysfunction was partially abrogated (based on Kir 4.1 protein and GSH content). The GS decrease was not prevented by dexamethasone, and AQP-4 was not altered in this epileptic model.

Conclusions: Changes in astroglial parameters emphasize the importance of these cells for understanding alterations and mechanisms of epileptic disorders in this model. In vivo dexamethasone administration prevented most of the parameters analyzed, reinforcing the importance of anti-inflammatory steroid therapy in the Li-pilocarpine model and possibly in other epileptic conditions in which neuroinflammation is present.
\end{abstract}

Keywords: Epilepsy, Dexamethasone, Neuroinflammation, Astrocytes, S100B

\footnotetext{
* Correspondence: adrianavizuete@gmail.com

Department of Biochemistry, Instituto de Ciências Básicas da Saúde,

Universidade Federal do Rio Grande do Sul, Ramiro Barcelos, 2600-Anexo,

Porto Alegre, RS 90035-003, Brazil
} 


\section{Background}

Epilepsy is a neuronal disorder characterized by recurrent and spontaneous seizures, resulting from excessive, abnormal, and hypersynchronous neuronal activity [1-3]. Approximately 50 million people worldwide suffer from this neuronal disorder, which normally affect mostly children and the elderly population [4]. Temporal lobe epilepsy (TLE) that affects the limbic system $[5,6]$ is the most common form of partial epilepsy and resistance to anticonvulsive drugs which develops in about $30 \%$ of cases $[7,8]$. The Li-pilocarpine-induced model of epilepsy exhibits similar hippocampal alterations to those observed in TLE patients $[9,10]$ and is accompanied by drug resistance [11].

Brain tissue samples from patients and experimental models show specific astroglial changes, mainly in the levels of glial fibrillary acidic protein (GFAP) and S100B protein [12-16]. In fact, results from several studies suggest that epileptogenesis involves changes in the glial cells beyond neuronal alterations $[17,18]$. Astrocytes are glial cells that interact with neurons and form tripartite synapses [19]. Some studies have strongly implicated astrocytes in the development of epileptic disorders [20-23]. Astrogliosis and neuroinflammation have been correlated to epileptogenesis, recurrent, and spontaneous seizures [2429]. For this reason, specific astroglial targets (e.g., S100B, glutamine synthetase (GS), potassium channel Kir 4.1, and water channel AQP-4) have been investigated with a view to improving therapeutic approaches and the development of antiepileptic drugs [30].

The $\mathrm{S} 100 \mathrm{~B}$ protein is a glial protein that is a widely used marker for brain injury conditions, including epileptic disorders [31, 32], and indeed displays an augmented secretion during brain injury condition, working as a neurotrophic cytokine or simply as a damageassociated molecular pattern (DAMP) [33]. Moreover, S100B secretion is modulated by LPS [34] and antiinflammatory drugs $[35,36]$. Chronically elevated extracellular levels of S100B potentially lead to neurodegenerative processes $[37,38]$.

Therapy with corticosteroids, such as dexamethasone palmitate, has been used to treat refractory epilepsy in children [39]. Dexamethasone has been shown to reduce seizures in epileptic encephalopathy patients [40, 41]; while dexamethasone use has been evaluated in the Lipilocarpine model of epilepsy [42, 43], its effect on astroglial targets has not been fully investigated. We hypothesized that dexamethasone mediates downregulation of S100B secretion and that this change could contribute to decrease neuroinflammation and astrogliosis during epileptogenesis. In fact, extracellular levels of S100B are elevated in Li-pilocarpine model of epilepsy [14].

Herein, we investigated the effect of dexamethasone on inflammatory and astroglial parameter in the $\mathrm{Li}$ pilocarpine model of epilepsy. Firstly, we evaluated the modulation of S100B secretion by dexamethasone in acute hippocampal slices at 1, 14, and 56 days after the induction of status epilepticus (SE) by Li-pilocarpine administration in young rats. In this experimental model, these times correspond approximately to the acute, silent, and chronic phases, respectively [44]. In the second set of experiments, we administered intraperitoneal dexamethasone 1 day after SE and analyzed inflammatory and hippocampal astroglial parameters (S100B, GFAP, GS, GSH, AQP-4, and Kir 4.1) at 1 and 56 days afterward. Cerebrospinal fluid (CSF) and serum S100B were also determined.

\section{Methods}

\section{Animals}

Male Wistar rats, at postnatal day 27, were used in this study. We focused this study on young (27-day-old) rats to characterize glial changes from an age corresponding to childhood in rats [45]. It is important to mention that, at this age, rats have developed and matured their bloodbrain barrier [46], energetic metabolism [47], and GABAergic neurotransmission [48]. Animals were obtained from our breeding colony (Department of Biochemistry, UFRGS) and maintained under controlled light and environmental conditions (12 h light/12 h dark cycle at a constant temperature of $22 \pm 1{ }^{\circ} \mathrm{C}$ ). Procedures were in accordance with the National Institutes of Health Guide for the Care and Use of Laboratory Animals (NIH Publications No. 8023) following the regulations of the local animal house authorities and Committee of Animal Use of UFRGS (project number 24472).

This study was divided into two parts. The first was to analyze the S100B secretion in the acute hippocampal slices in animals submitted to the Li-pilocarpine epileptic model. The second part was to observe the in vivo effects of dexamethasone on inflammatory and astroglial parameters in the model (Additional file 1).

\section{Epilepsy model}

Animals were subjected to the LiCl-pilocarpine model of TLE, according to Cavalheiro [9]. Briefly, the rats were treated intraperitoneally with lithium $(\mathrm{LiCl}, 3 \mathrm{mEq} / \mathrm{kg}$, i.p.) $12-18 \mathrm{~h}$ prior to the administration of pilocarpine (45 mg/kg, i.p.) (Sigma, St. Louis, MO, USA). Sham animals also received $\mathrm{LiCl}$ at $12-18 \mathrm{~h}$ prior to saline $(0.9 \%$ $\mathrm{NaCl}$, i.p.) administration. Animals were monitored and classified into five stages of an epileptic seizure, according to Racine's scale: (1) mouth and facial movement, (2) head nodding, (3) forelimb clonus, (4) rearing with forelimb clonus, and (5) rearing and falling with forelimb clonus.

We considered SE when animals reached stage 4 and stayed at this stage for more than $30 \mathrm{~min}$. SE induction was stopped after 90 min by administration of diazepam 
(10 $\mathrm{mg} / \mathrm{kg}$, i.p.) followed by four administrations of HBSS medium (at 1.5, 7, 12, and $24 \mathrm{~h}$ after SE onset) containing (in mM) $137 \mathrm{NaCl}, 0.63 \mathrm{Na}_{2} \mathrm{HPO}_{4}, 4.17$ $\mathrm{NaHCO}_{3}, 5.36 \mathrm{KCl}, 0.044 \mathrm{KH}_{2} \mathrm{PO}_{4}, 1.26 \mathrm{CaCl}_{2} .2 \mathrm{H}_{2} \mathrm{O}$, $0.041 \mathrm{MgSO}_{4} .7 \mathrm{H}_{2} \mathrm{O}, 0.049 \mathrm{MgCl}_{2} .6 \mathrm{H}_{2} \mathrm{O}$, and 5.55 glucose, in order to promote a better animal recovery.

For further experiments, only animals that reached stage 4 and presented recurrent seizures were used. These animals were analyzed at different times-1, 14, and 56 days after pilocarpine injection-which correspond to the acute, latent, and chronic phases of epilepsy induced by the Li-pilocarpine model [49].

\section{First study-evaluation of S100B secretion in the acute hippocampal slices of SE rats}

Sixty male rats were divided into (1) sham and (2) SE animals at different times $(1,14$, and 56 days) after pilocarpine injection. These animals were killed by decapitation, and their brains were removed and placed in a cold saline medium of the following composition (in $\mathrm{mM}$ ): $120 \mathrm{NaCl}, 2 \mathrm{KCl}, 1 \mathrm{CaCl}_{2}, 1 \mathrm{MgSO}_{4}, 25 \mathrm{HEPES}, 1$ $\mathrm{KH}_{2} \mathrm{PO}_{4}$, and 10 glucose, adjusted to $\mathrm{pH}$ 7.4. The hippocampi were dissected, and transverse slices of $0.3 \mathrm{~mm}$ were obtained using a McIlwain Tissue Chopper. Slices were then transferred immediately into 24-well culture plates, each well containing $0.3 \mathrm{ml}$ of saline medium and only one slice. The medium was replaced every $15 \mathrm{~min}$ with fresh saline medium at room temperature. Following a $120-$ min equilibration period, the medium was removed and replaced with basal or specific treatments (high potassium-30 mM KCl; $0.1 \mu \mathrm{M}$ dexamethasone; vehicle-0.01\% DMSO) for $60 \mathrm{~min}$ at $30{ }^{\circ} \mathrm{C}$ on a warming plate [50].

\section{S100B secretion}

S100B content in the supernatant was measured by ELISA, as described previously [51]. Briefly, $50 \mu \mathrm{l}$ of sample plus $50 \mu \mathrm{l}$ of Tris buffer were incubated for $2 \mathrm{~h}$ on a microtiter plate that was previously coated with monoclonal anti-S100B SH-B1 (Sigma-Aldrich, St. Louis, MO, USA). Polyclonal anti-S100 (Dako, Carpinteria, CA, USA) was incubated for $30 \mathrm{~min}$, and peroxidase-conjugated anti-rabbit antibody was then added for a further $30 \mathrm{~min}$. The color reaction with OPD was measured at $492 \mathrm{~nm}$. The standard S100B curve ranged from 0.02 to10 ng/ml and data expressed as nanograms per milligram or nanograms per milliliter. Results are shown as percentages of the control.

\section{Lactate dehydrogenase assay}

Slice integrity was evaluated by lactate dehydrogenase (LDH) kinetic activity using a commercial kit (BioClin, Brazil). The assay was performed according to the manufacturer's instructions.
Second study-effect of dexamethasone on the SE model Sixty male rats received an administration of vehicle (DMSO, $0.1 \%$, i.p.) or dexamethasone $(10 \mathrm{mg} / \mathrm{kg}$, i.p.) 24 and $36 \mathrm{~h}$ after SE induction by LiCl-pilocarpine administration. Groups of animals were divided into (1) sham + vehicle, (2) SE + vehicle, and (3) SE + dexamethasone at 1 and 56 days after pilocarpine injection. Herein, the animals were monitored between 1 and 56 days after SE induction and dexamethasone administration. They were video monitored every other day, 4-5 $\mathrm{h}$ for behavioral evaluation of occurrence of recurrent spontaneous seizures. All SE animals developed epileptic behavior, i.e., all animals exhibited, at least, score 2 in the Racine's scale between 7 and 25 days after SE induction. Dexamethasone did not change epileptic behavior (see Additional file 2).

\section{Brain tissue, serum, and CSF samples}

Rats were anesthetized by intraperitoneal injection of ketamine $(75 \mathrm{mg} / \mathrm{kg})$ and xylazine $(10 \mathrm{mg} / \mathrm{kg})$, and the blood was collected by cardiac puncture; serum was obtained by centrifuging at $1000 \times g$ for $10 \mathrm{~min}$ (Eppendorf 5402 , Hamburg, Germany) before storing at $-80{ }^{\circ} \mathrm{C}$. For ventricular access, the anesthetized rats were placed in a stereotaxic apparatus and cerebrospinal fluid (CSF) was obtained carefully by puncturing the cisterna magna with an insulin syringe. A maximum volume of $30 \mu \mathrm{l}$ was collected over a 3-min period to minimize the risk of brain stem damage. The hippocampi were dissected, and transverse slices of $0.3 \mathrm{~mm}$ were obtained using a McIlwain Tissue Chopper as described above. Samples were stored at $-80{ }^{\circ} \mathrm{C}$ until biochemical and immunological assays.

\section{Cytokines and prostaglandin E2 measurement}

The hippocampal slices were homogenized in phosphate buffer saline (PBS) containing (in $\mathrm{mM}$ ) $50 \mathrm{NaCl}, 18$ $\mathrm{Na}_{2} \mathrm{HPO}_{4}$, and $83 \mathrm{NaH}_{2} \mathrm{PO}_{4} \cdot \mathrm{H}_{2} \mathrm{O}$, pH 7.4, with $1 \mathrm{mM}$ EGTA and $1 \mathrm{mM}$ phenylmethylsulphonyl fluoride (PMSF), followed by centrifugation at $1000 \times g$ for $5 \mathrm{~min}$ at $4{ }^{\circ} \mathrm{C}$. Cytokines were measured in supernatants using rat TNF- $\alpha$, IL-1 $\beta$, IL-10 (eBioscience, San Diego, USA), and PGE2 (Enzo Life Science, Farmingdale, NY, USA) ELISA kits. Serum TNF- $\alpha$ content was also evaluated. Data are expressed in picograms per milligram protein (tissue samples) or picogram per milliliter (serum).

\section{S100B measurement}

Slices were homogenized in PBS with $1 \mathrm{mM}$ EGTA and $1 \mathrm{mM}$ PMSF. The S100B content in the CSF, serum, and brain tissue was measured by ELISA, as described above. Data are expressed in nanograms per milligram protein (tissue samples) or nanogram per milliliter (CSF and serum). 


\section{GFAP measurement}

GFAP content was measured by ELISA, as described previously [52]. The ELISA for GFAP was carried out by coating wells of 96-well plates with $100-\mu$ l samples containing $70 \mu \mathrm{g}$ of protein overnight at $4{ }^{\circ} \mathrm{C}$. Wells were incubated with a polyclonal anti-GFAP antibody (Dako, Carpinteria, CA, USA) from rabbit for $2 \mathrm{~h}$, followed by incubation with a secondary antibody conjugated with peroxidase for $1 \mathrm{~h}$, at room temperature. The color reaction with OPD was measured at $492 \mathrm{~nm}$. The standard GFAP (Calbiochem, San Diego, CA, USA) curve ranged from 0.1 to $10 \mathrm{ng} / \mathrm{ml}$. Data are expressed in nanogram per milligram protein.

\section{Glutamine synthetase activity}

The enzymatic assay for glutamine synthetase (GS) was performed, as described previously [53] with modifications. Briefly, the hippocampal slices were homogenized in $50 \mathrm{mM}$ imidazole buffer. Homogenates were then incubated with (mM) 50 imidazole, 50 hydroxylamine, 100 L-glutamine, 25 sodium arsenate dibasic heptahydrate, 0.2 ADP, and 2 manganese chloride, $\mathrm{pH} 6.2$ for $15 \mathrm{~min}$ at $37{ }^{\circ} \mathrm{C}$. The reactions were terminated by the addition of $0.2 \mathrm{ml}$ of $0.37 \mathrm{M} \mathrm{FeCl}_{3}, 200 \mathrm{mM}$ trichloroacetic acid, and $670 \mathrm{mM} \mathrm{HCl}$. After centrifugation, supernatant absorbance was measured at $530 \mathrm{~nm}$. The standard $\gamma$ glutamylhydroxamate acid (Sigma-Aldrich, St. Louis, MO, USA) curve ranged from 0.1 to $10 \mathrm{mmol} / \mathrm{ml}$. GS activity is expressed as $\mu \mathrm{mol} / \mathrm{h} / \mathrm{mg}$ protein.

\section{Glutathione content}

Reduced glutathione (GSH) content was determined based on [50]. Briefly, slices were homogenized in sodium phosphate buffer (0.1 M, pH 8.0), and protein was precipitated with $1.7 \%$ meta-phosphoric acid. $O$-phthaldialdehyde ( $1 \mathrm{mg} / \mathrm{ml}$ methanol) (Sigma) was added to the supernatant at room temperature for $15 \mathrm{~min}$. Fluorescence was measured using excitation and emission wavelengths of 350 and $420 \mathrm{~nm}$, respectively. The standard calibration glutathione (Sigma-Aldrich, St. Louis, MO, USA) solution curve ranged from 0 to $500 \mu \mathrm{M}$. Glutathione results are expressed as nanomoles per milligram protein.

\section{Western blotting}

Nitrocellulose membranes were blocked overnight at $4^{\circ}$ $\mathrm{C}$ with $2 \%$ bovine serum albumin (BSA) in Tris-buffered

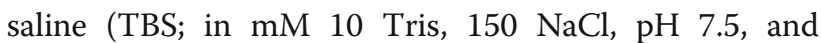
$0.05 \%$ Tween $20^{\circ}$ ) and then incubated overnight at $4{ }^{\circ} \mathrm{C}$ in blocking solution containing the following antibodies: anti-Kir 4.1, anti-AQP-4, anti-COX1, anti-COX2 (diluted 1:1000), and anti-GS (diluted 1:10,000) (Santa Cruz Biotechnology, Inc., Dallas, TX, USA), and anti-actin (1:2000) (Sigma). Subsequently, the membranes were incubated for $1 \mathrm{~h}$ at room temperature in a solution containing horseradish peroxidase (HRP)-conjugated anti-rabbit IgG (diluted 1:10,000), HRP anti-mouse IgG (diluted 1:10,000) (GEHealthcare, Sao Paulo, Brazil), or HRP anti-goat diluted 1:10000 (Sigma). A chemiluminescence signal was detected by luminol substrate reaction (ECL Western Blotting System, GEHealthcare ${ }^{\oplus}$ ). Immunoblots were quantified by membrane scanning in an Image4000, GE Healthcare ${ }^{\bullet}$, and optical densities of proteins studied were determined by ImageJ software (Packard Instrument Company) and the protein/actin ratio calculated.

\section{Protein measurement}

Protein was measured by Lowry's method, modified by Peterson, using bovine serum albumin as a standard [54].

\section{Statistical analysis}

All results were expressed as mean \pm standard error mean (SEM) and analyzed by one-way analysis of variance (ANOVA) followed by Tukey's or Dunnett's test. The level of statistical significance was set at $p<0.05$. All analyses were performed using the Prism 5.0 software (GraphPad).

\section{Results \\ S100B secretion in the acute hippocampal slices of epileptic rats}

All animals from the Li-pilocarpine group, used in neurochemical assays, reached at least phase 4 of the convulsive Racine's scale within 13 min after pilocarpine administration (data not shown). At 1, 14, and 56 days after Li-pilocarpine injection, we analyzed basal S100B secretion or S100B secretion in the presence of dexamethasone or in high-potassium medium in the acute hippocampal slices from sham and Li-pilocarpine-treated animals (Fig. 1).

S100B secretion in the hippocampal slices from sham animals is presented in panels a, c, and e, which correspond to 1, 14, and 56 days after saline administration. Li-pilocarpine-treated animals are shown in panels b, d, and $f$. Basal secretion did not differ between the sham and Li-pilocarpine-treated rats at all times (data not shown) and was assumed as $100 \%$. Dexamethasone downregulated $\mathrm{S} 100 \mathrm{~B}$ secretion $(p=0.0073$ in a, $p=$ 0.0184 in $\mathrm{c}$, and $p=0.0171$ in e) in high-potassium medium at all times analyzed. Ex vivo S100B secretion of the hippocampi after SE induction of rats by $\mathrm{Li}$ pilocarpine was not different in the normal- or highpotassium medium for all times analyzed. However, dexamethasone downregulated $\mathrm{S} 100 \mathrm{~B}$ secretion at 1 (panel b) and 56 days (panel $\mathrm{f}$ ) following SE induction ( $p=0.0184$ and $p=0.0171$, respectively). Dexamethasone 

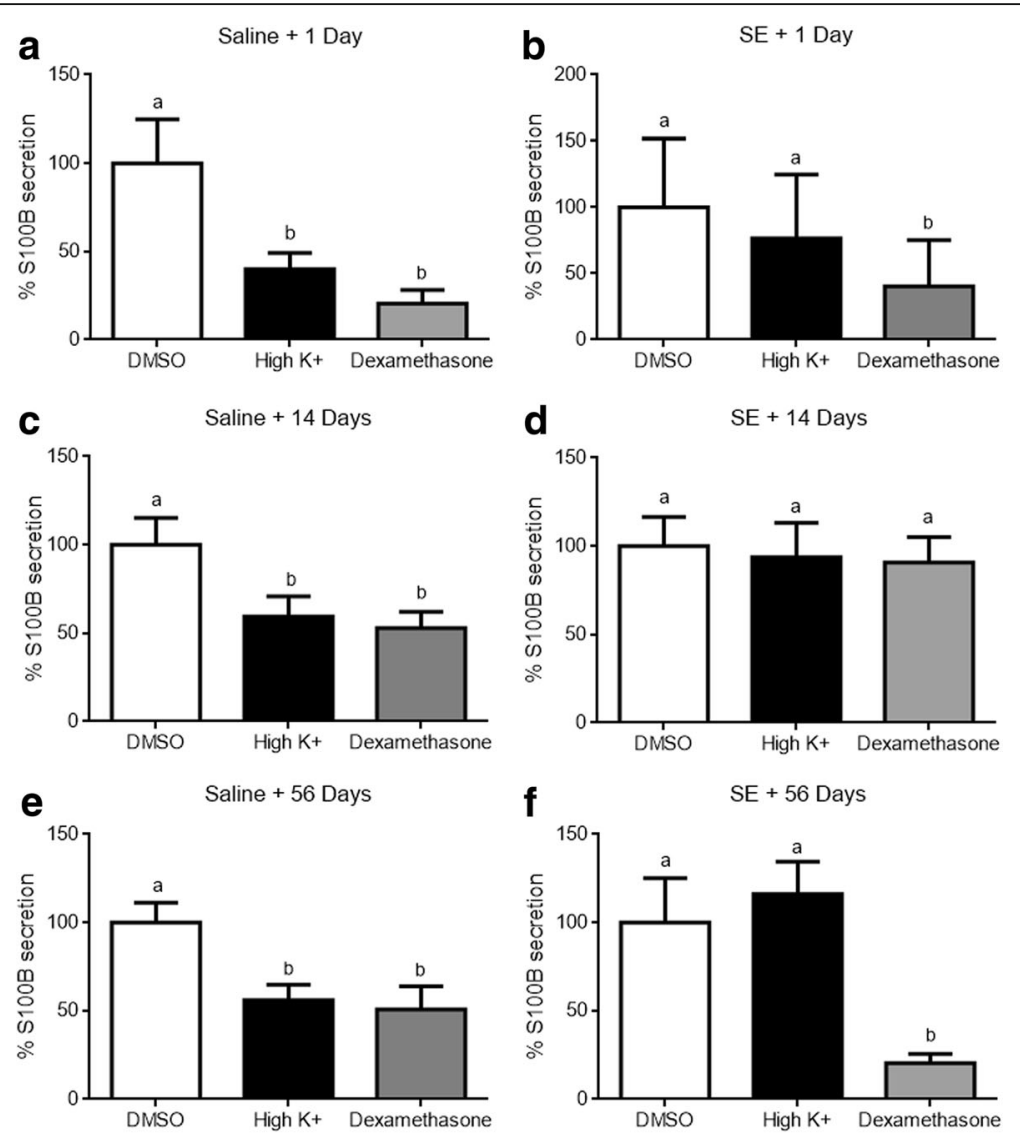

Fig. 1 Dexamethasone and high potassium levels modulate S100B secretion in the acute hippocampal slices. S100B secretion from the hippocampus was measured by ELISA. Dexamethasone and high potassium levels decreased S100B secretion in sham (saline) animals at 1, 14, and 56 days (a, c, e). Dexamethasone reduced S100B secretion at 1 and 56 days after pilocarpine injection. SE animals were not affected by high potassium at 1, 14, and 56 days $(\mathbf{b}, \mathbf{d}, \mathbf{f})$. Data are expressed as percentages compared to the basal condition and values represent mean \pm standard error, of six to eight animals per group. Data were analyzed by ANOVA, followed by the Dunnet test. Bars without a common letter differ significantly, assuming $p<0.05$

did not affect S100B secretion at 14 days (panel c) after SE induction $(p=0.9242)$.

\section{In vivo dexamethasone prevents the increment in inflammatory cytokines, prostaglandin E2 and, cyclooxygenases}

Dexamethasone, administered at 24 and $36 \mathrm{~h}$ after SE induction, was able to prevent inflammatory signals of hippocampal inflammation caused by SE induction (Fig. 2). Dexamethasone prevented the augmentation in IL-1 $\beta$ (panel a) and PGE2 (panel c) levels in the hippocampus of SE animals at 1 day after pilocarpine injection ( $p=0.0001$ and $p=0.0002$, respectively). The treatment with dexamethasone reduced TNF- $\alpha$ levels (panel b) when compared with SE and sham animals $(p=0.0286)$. No change was observed in IL-10 at 1 day after SE, and dexamethasone did not affect the levels of this antiinflammatory cytokine at this time ( $p=0.9221$; panel d). However, interestingly, we observed an increase in hippocampal IL-10 in dexamethasone-treated animals at day 56 after SE ( $p=0.0165$, panel e). At 56 days after SE, the increment in PGE2 was not significant $(p=0.572$; panel f) and dexamethasone did not affect this parameter.

The cyclooxygenase (COX1 and 2) content was measured by Western blotting (Fig. 3). The immunocontent of COX1 was the same in all groups at 1 (panel c) and 56 (panel d) days $(p=0.8938$ and $p=0.4244$, respectively). However, dexamethasone prevented the increase in COX2 at 1 (panel e) and 56 (panel f) days ( $p=0.0109$ and $p=0.00913$, respectively).

Dexamethasone prevents astrogliosis markers, GFAP, and $\mathrm{S} 100 \mathrm{~B}$ in the epileptic model

The increment in GFAP, induced in the Li-pilocarpine model of epilepsy, was prevented by dexamethasone in animals at 1 (Fig. 4a) and 56 (Fig. 4b) days after pilocarpine injection ( $p=0.0035$ and $p=0.0245$, respectively). Hippocampal S100B content also increased following SE induction (Fig. 5a, b), and this was prevented by dexamethasone (panel c, $p=0.0062$ ). However, the elevation in hippocampal S100B at 56 days in SE animals was 

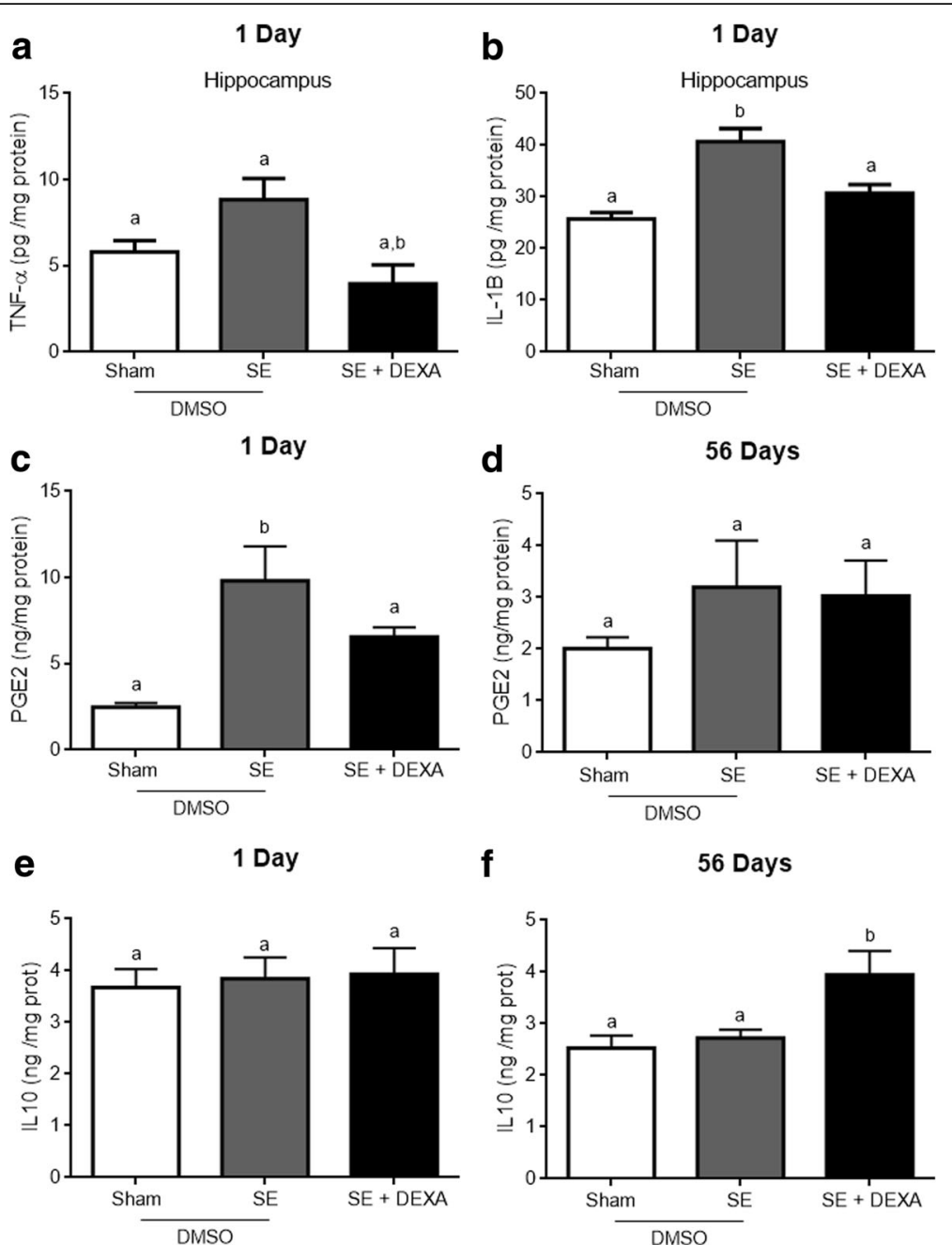

f

56 Days

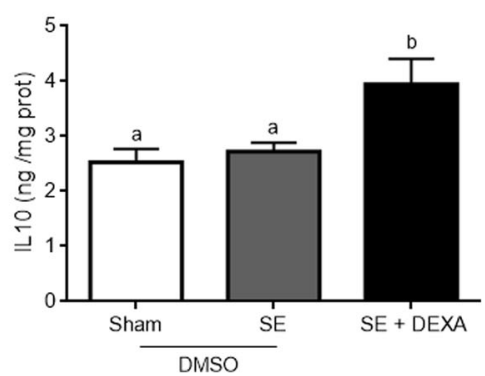

Fig. 2 Dexamethasone prevents neuroinflammation in the hippocampus. Pro-inflammatory and anti-inflammatory cytokines were measured by ELISA. Dexamethasone decreased TNFa (a), reversed IL-1 $\beta$ (b), and PGE-2 (c) levels at 1 day after treatment. Dexamethasone did not affect PGE2 (d) content at 56 days nor IL-10 levels at 1 day after treatment. At 56 days, dexamethasone increased IL-10 content. Values were expressed by mean \pm standard error, of four to six animals per group. Data were analyzed by ANOVA, followed by the Tukey test. Bars without a common letter differ significantly, assuming $p<0.05$

partially prevented by dexamethasone administration (panel b, $p=0.0445$ ).

\section{Dexamethasone prevented the increment in cerebrospinal} fluid S100B during the chronic phase of the epileptic model CSF S100B content was increased after SE induction at 1 (panel c) and 56 (panel d) days ( $p=0.0125$ and $p=0.0096$, respectively). Dexamethasone was unable to prevent this increase at 1 day after pilocarpine administration (panel c). However, it completely prevented the elevation in CSF S100B at 56 days (panel c). Serum S100B content diminished in SE animals at 1 day $(p=0.0005$; panel e), and dexamethasone did not affect this change. At 56 days, serum S100B was not different in SE animals or affected by dexamethasone ( $p=0.3719$; panel e).
Dexamethasone prevents the decrease in glutathione in the Li-pilocarpine model of epilepsy

Based on the astrogliosis signals found in this model, we investigated other astroglial parameters related to astrocyte functionality, namely, glutamine synthetase (GS) activity, GSH content, potassium channel Kir 4.1, and aquaporin-4 (AQP-4). GS activity decreased in epileptic animals (Fig. 6) at 1 (panel a) and 56 (panel b) days ( $p=$ 0.0003 and $p=0.0030$, respectively), and dexamethasone did not prevent this change at 1 or 56 days. However, we found a decrease in the hippocampal GSH content at 1 (panel c) and 56 (panel d) days $(p=0.0174$ and $p=$ 0.0500 , respectively), possibly reflecting astroglial dysfunction, and dexamethasone administration completely prevented this alteration. In fact, GSH content is not an appropriate marker for astrocytes, but in the brain 

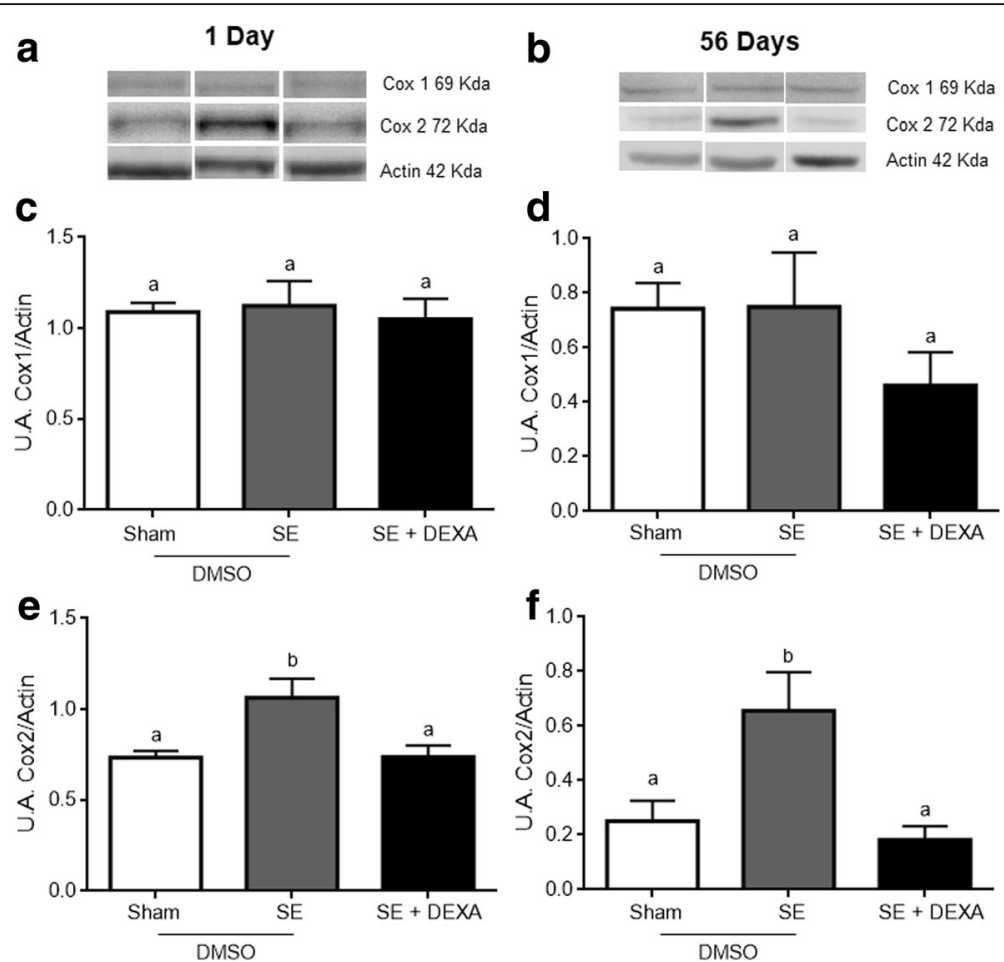

Fig. 3 Dexamethasone prevents COX2 content in the hippocampus. COX1 and COX2 content were measured by Western blot. Representative images of COX1 and COX2 in the hippocampus at 1 and 56 days after treatment (a, b). Chemiluminescent quantification of protein/actin of COX 1 (c, d) and COX $2(\mathbf{e}, \mathbf{f})$. Dexamethasone prevented the increase in COX2 content in the hippocampus of SE animals at 1 and 56 days after treatment (e and $\mathbf{f}$, respectively). Values represent mean \pm standard error, of four to six animals per group. Data were analyzed by ANOVA, followed by the Tukey test. Bars without a common letter differ significantly, assuming $p<0.05$

tissue, its synthesis and recycling are totally dependent on astrocyte activity.

\section{Dexamethasone prevents the impairment in potassium uptake by astrocytes in epileptic rats}

Levels of the Kir 4.1 protein, the main potassium channel in astrocytes, was lower in epileptic rats at 1 (Fig. $7 \mathrm{c})$ and 56 (Fig. 7d) days ( $p=0.0024$ and $p=0.0418$, respectively), and dexamethasone was able to prevent this effect at
56 days after SE induction, but not at 1 day after. There were no differences in AQP-4 levels in epileptic animals at 1 (Fig. 7e) and 56 (Fig. 7f) days ( $p=0.6905$ and $p=0.1419$, respectively), and dexamethasone did not affect AQP-4 content at 1 and 56 days after SE induction.

\section{Discussion}

Most AED target neuronal activity modulated by ionic channels, particularly $\mathrm{GABA}_{\mathrm{A}}$. The steroid sensitivity of
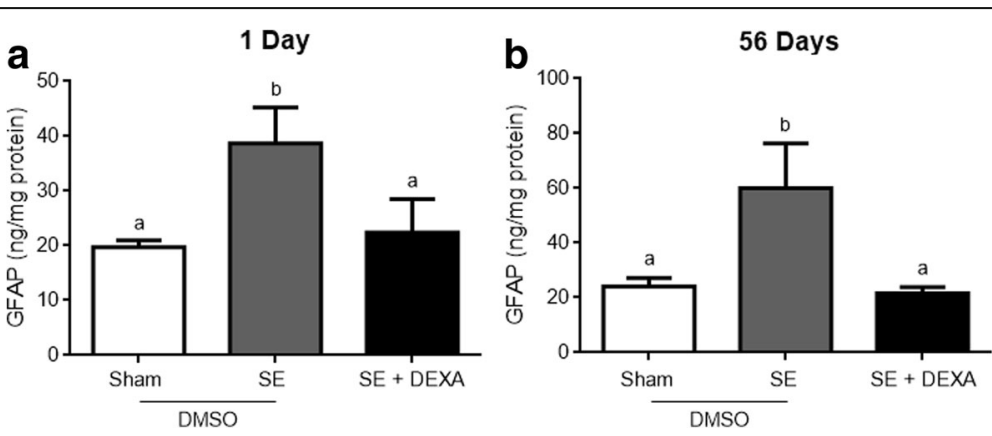

Fig. 4 Dexamethasone prevents astrogliosis in the hippocampus. GFAP was measured by ELISA. Dexamethasone prevented the increase in GFAP content in the hippocampus of SE animals at 1 and 56 days after treatment (a and $\mathbf{b}$, respectively). Values represent mean \pm standard error, of four to six animals per group. Data were analyzed by ANOVA, followed by the Tukey test. Bars without a common letter differ significantly, assuming $p<0.05$ 

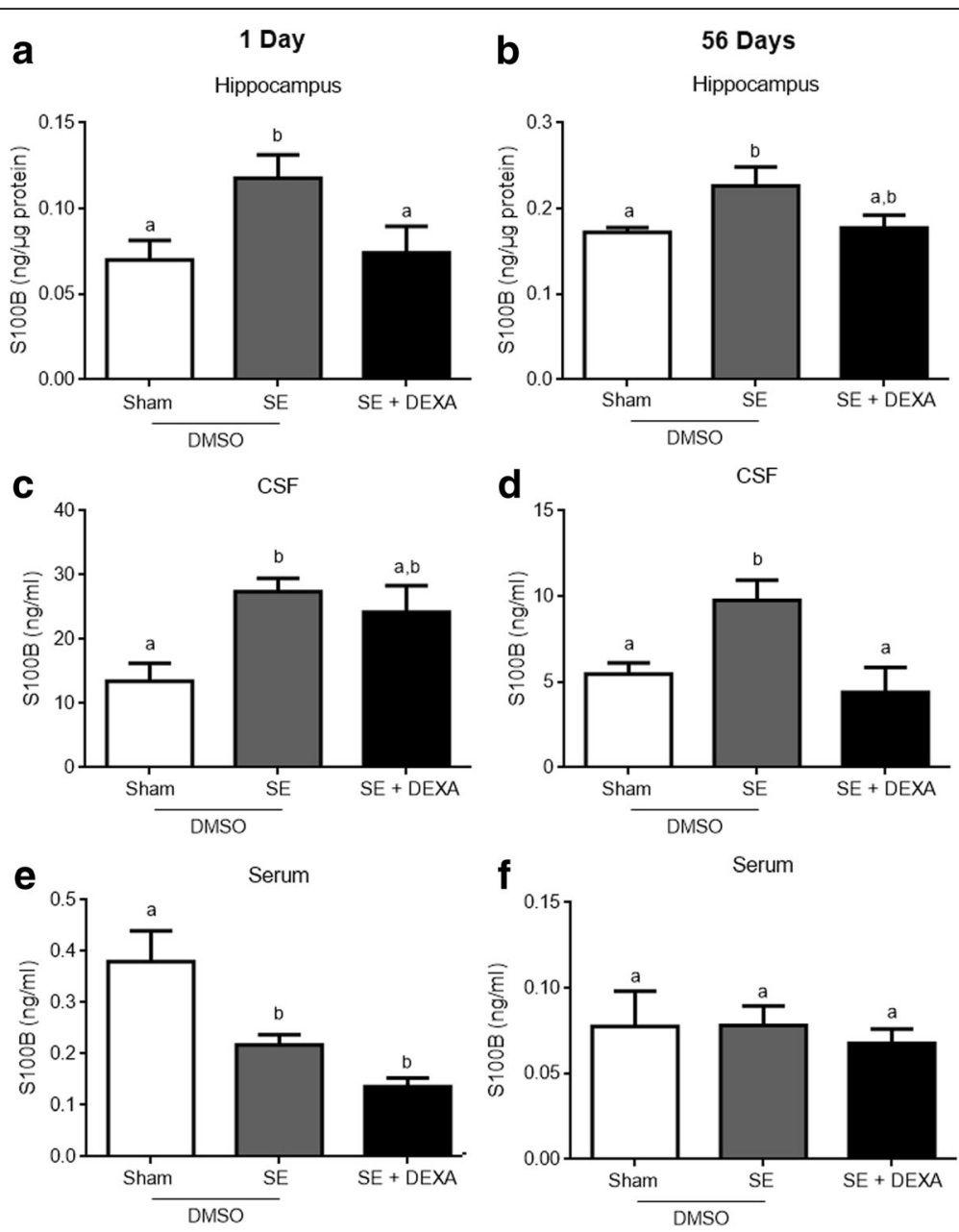

Fig. 5 Dexamethasone modulates S100B levels in the hippocampus and in the cerebrospinal fluid. S100B content was measured by ELISA. Dexamethasone prevented the augmentation in S100B content in the hippocampus of SE animals at 1 day after treatment (a) and did not affect S100B content at 56 days after SE induction (b). The augmentation in S100B levels in the CSF was prevented by dexamethasone at 56 days after SE induction (d). Serum S100B levels were not altered by dexamethasone at any of the time points (e, f). Values represent mean \pm standard error, of four to six animals per group. Data were analyzed by ANOVA, followed by the Tukey test. Bars without a common letter differ significantly, assuming $p<0.05$

these channels has led to the use of steroids as adjunctive drugs for epilepsy [55-57]. Moreover, 30\% of TLE patients develop resistance to AED [58], and additional strategies for therapeutic approaches are welcome. Mounting evidence suggests that astrocytes and neuroinflammation (which is modulated by astrocytes and microglia in brain tissue) contribute to epileptogenesis and are potential targets for therapies being developed against epileptic disorders [59].

\section{Dexamethasone affects S100B secretion}

As previously mentioned, $\mathrm{S} 100 \mathrm{~B}$ is widely used as a marker for epileptic disorders [31,32], and its secretion is modulated by anti-inflammatory drugs $[35,36]$. Our studies have suggested that the hippocampal and CSF S100B are altered after SE induction in the Li-pilocarpine model
[14]. We, herein, confirm that the hippocampal slices incubated in high-potassium medium secrete less S100B $[60,61]$; this effect was observed in slices from young (14 days old) and adult (70 days old) sham rats. The mechanism underlying this decrease in S100B secretion remains unclear and could be mediated by an undetermined neuronal factor released during high-potassium depolarization, such as glutamate [60]. On the other hand, a direct effect of high-potassium on potassium channels and transporters in astrocytes modulating S100B secretion cannot be ruled out [61].

However, in the hippocampal slices from rats submitted to the Li-pilocarpine model of epilepsy, S100B secretion did not change in high-potassium medium, although the reason for this lack of change in S100B secretion is unclear at the moment [60], as is the mechanism by which 

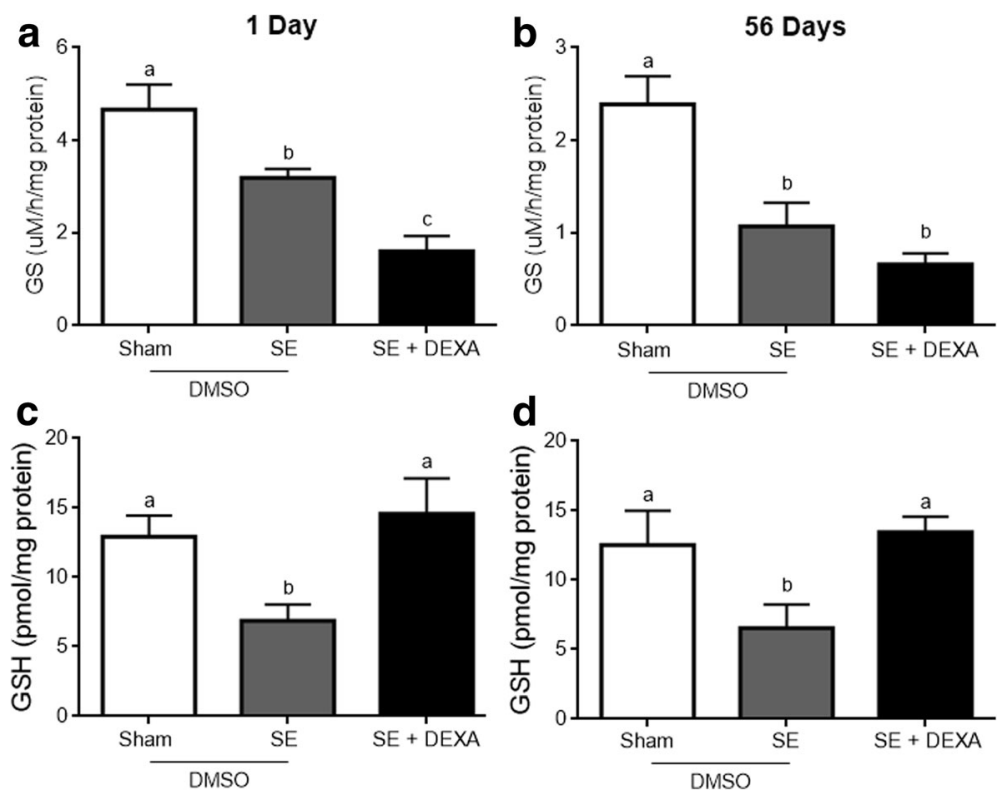

Fig. 6 Dexamethasone does not modulate decreased GS activity but reverses GSH content in the hippocampus. The decrease in GS activity was not modulated by dexamethasone in the SE animals $(\mathbf{a}, \mathbf{b})$. Dexamethasone prevented the reduction in GSH reduced at 1 and 56 days after treatment $(\mathbf{c}, \mathbf{d})$. Values represent mean \pm standard error, of four to six animals per group. Data were analyzed by ANOVA, followed by Tukey test. Bars without a common letter differ significantly, assuming $p<0.05$
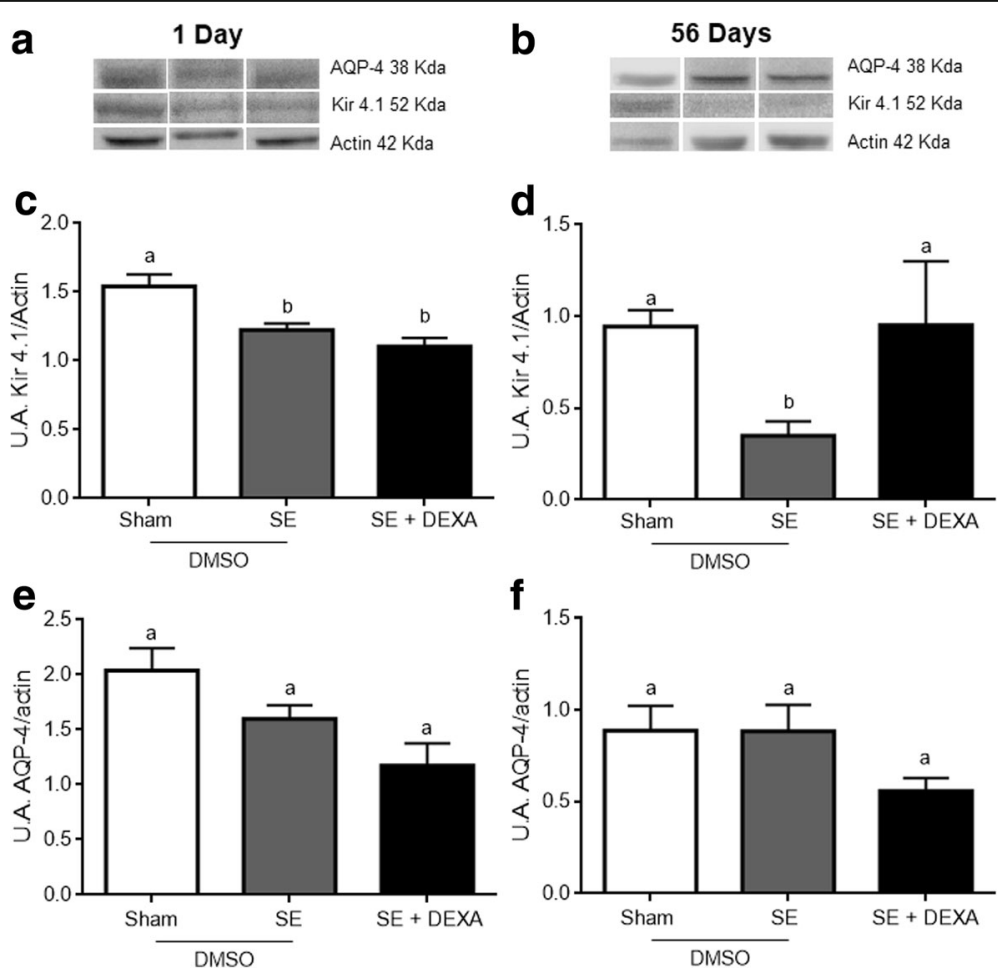

Fig. 7 Dexamethasone does not alter Kir 4.1 and AQP-4 astrocyte channel content in the hippocampus. Kir 4.1 and AQP-4 contents were determined by Western blot. Representative images of Kir 4.1 and AQP-4 in the hippocampus at 1 and 56 days after treatment (a, b). Chemiluminescent quantification of Kir 4.1 (c, d) and AQP-4 (e, f) protein/actin. Dexamethasone did not reverse the reduction in Kir 4.1 content in the hippocampus of SE animals at 1 day after treatment (c); however, dexamethasone prevented Kir4.1 content in SE animals at 56 days after treatment (d). No differences in AQP-4 channel expression were observed between groups (e, $\mathbf{f}$. Values represent mean \pm standard error, of four to six animals per group. Data were analyzed by ANOVA, followed by Tukey test. Bars without a common letter differ significantly, assuming $p<0.05$ 
S100B secretion occurs [37]. However, it is possible that the decrease in potassium channels in SE animals may contribute to the lower potassium influx in the astrocytes of these animals $[49,62,63]$.

A number modulators of S100B secretions have been described [38]. Dexamethasone per se decreased S100B secretion in the acute hippocampal slices from sham animals (at all analyzed times) and in SE animals (at 1 and 56 days after pilocarpine administration). No in vitro effect of dexamethasone occurred at 14 days after SE, which corresponds to the "silent period" of this model [44]. Interestingly, these time-dependent changes in S100B secretion of the hippocampal slices of SE animals coincide with changes of this protein observed in CSF in the Li-pilocarpine model of epilepsy [14]. The acute effect of dexamethasone on the epileptiform activity of the hippocampal slices has been previously reported [64], but the mechanism underlying this activity remains unclear. Based on the effect of dexamethasone on S100B secretion at 1 day after SE induction, we decided to investigate whether dexamethasone administration at 24 and $36 \mathrm{~h}$ after pilocarpine injection prevents changes in inflammatory and astroglial markers at 1 and 56 days after dexamethasone injection.

\section{In vivo dexamethasone prevents neuroinflammation}

The long-term effect of dexamethasone observed in astroglial and inflammatory parameters involves changes in gene expression, whereby dexamethasone prevents the increase in IL-1 $\beta$, TNF- $\alpha$, and COX2 (and consequently PGE2 levels) in the hippocampus of SE animals at 1 day after dexamethasone administration. Of note, in SE animals treated with dexamethasone, TNF- $\alpha$ was decreased to levels that were lower than those of sham animals, but unfortunately, we did not carry out cytokine measurements in the sham group without dexamethasone. Furthermore, dexamethasone increased IL-10, an anti-inflammatory cytokine, in SE animals at 56 days. Taken together, these data suggest the induction of a non-inflammatory microenvironment by dexamethasone in the hippocampus of Li-pilocarpine-treated animals over the short and long term.

\section{Dexamethasone prevents astrogliosis}

Based on two classical glial markers, GFAP and S100B, we found that dexamethasone administration at 24 and $36 \mathrm{~h}$ after pilocarpine-induced SE administration was able to prevent astrogliosis. It is well known that GFAP and $\mathrm{S} 100 \mathrm{~B}$ expressions are downregulated in glial cultures by dexamethasone $[36,65]$ and that the in vivo administration of this corticoid has been used to reduce the inflammatory response and gliosis [66, 67]. Moreover, although dexamethasone was not able to reduce CSF S100B during a short time (2 days after SE), it was effective later on (at 56 days after SE). This effect may be of relevance as chronically elevated levels of this protein contribute to neurodegenerative diseases [37, 38]. Notably, we found a decrease in serum S100B after SE. This could be due to brain "retention" of this protein, as proposed in some cases of acute brain injury [68] or could be due to its peripheral alteration (independent of brain source) [69]. It is also important to mention that, in another model of SE induction using scopolamine/ pilocarpine, an increase in serum S100B was reported and that the previous administration of dexamethasone prevented this increment [70].

\section{Dexamethasone protects against astrocyte dysfunction}

Glutamine synthetase (GS) is a specific astrocyte enzyme that is critical to glutamate metabolism in the brain and closely related to glutamatergic and gabaergic neurotransmission and reduced in the human hippocampus in TLE [71]. A reduced expression of GS was reported at 2 weeks after SE in the Li-pilocarpine model [72]. In this study, we detected an earlier decrease in GS that persisted until the chronic phase. It is well known that dexamethasone induces the expression of this enzyme [73]; however, inflammatory cytokines are able to block this induction in astrocyte cultures [74]. We assumed that the hippocampal GS decrease in the Li-pilocarpine model is due to inflammation, but it is unclear at the moment why dexamethasone did not prevent this effect. It is possible that this effect may depend on the dose and time of corticoid administration. On the other hand, the hippocampal oxidative stress observed in this model $[75,76]$, characterized here by the decrease in GSH, was completely reversed by dexamethasone administration. Rosiglitazone, an agonist of the peroxisome proliferatoractivated receptor gamma that has anti-inflammatory activity, also prevented the GSH imbalance in the hippocampus after pilocarpine-induced SE [77].

Neuronal excitability is highly dependent on extracellular levels of $\mathrm{K}^{+}$, which are regulated mainly by the astrocytic Kir 4.1 potassium channels that are in turn functionally coupled to the AQP-4 water channels [30]. In a previous study reporting on the induction of SE in rats with pilocarpine (without lithium), an increase in Kir 4.1 in the cortical regions, but not in the hippocampus, was observed at 8 weeks after SE induction [78]. We found an early (2 days after SE) and persistent (56 days after SE) decrease in Kir 4.1 content in the hippocampus. This apparently contradictory result is possibly due to methodological differences. Dexamethasone prevented the decrease in Kir 4.1 at 56 days after SE induction, but not at 1 day afterward. Accordingly, in the eye retina, dexamethasone (used to treat macular edema) selectively upregulated Kir 4.1 (but not AQP-4) channels [79]. Regardless of the changes in Kir 4.1 
observed in SE animals, no changes in AQP-4 were observed in this model.

The use of corticosteroid therapy for epilepsy disorders is a matter of debate, due to the pro- and anticonvulsive effects observed. Experimental studies have administered dexamethasone before SE induction and observed behavioral alterations, changes in the latency period of SE, and mortality, biochemical, neurological, and inflammatory modifications [42, 80, 81]. However, if dexamethasone administration occurred during SE, there were no changes in latency period, increased mortality ratio, and exacerbated cerebral edema [43]. Data relating to COX2 expression in the experimental models suggests that the corticoid effect depends on the dose, the time point of administration, the type of inhibitor (selective or non-selective), and differences among models of SE induction [82].

Although dexamethasone clearly prevented astroglial and inflammatory changes, commonly associated to epileptogenesis, it did not alter the epileptic behavior, such as the beginning of recurrent spontaneous seizures and the scores on Racine's scale (Additional file 2). We are assuming that dexamethasone effect involves a mechanism (direct or indirect) that alters the expression of these glial proteins, as it does with inflammatory proteins (cytokines and COX2). In fact, GFAP, GS, and S100B gene expression are sensitive to dexamethasone and cytokines $[36,83]$. GS and GFAP exhibit differing sensitivities to dexamethasone in the hippocampus [36]. Herein, we observed that these proteins are differentially affected in the epilepsy model and that dexamethasone administration did not prevent the change in GS. Kir 4.1 and AQP4 work together in the brain tissue to provide $\mathrm{K}^{+}$and water clearance [30]. However, these channels were not affected in the same manner in this model of epilepsy-indicating impairment in the ability to remove $\mathrm{K}^{+}$. Moreover, to our knowledge, there are no data in the literature regarding the effect of dexamethasone on the gene expression of Kir 4.1; the administration of this corticosteroid prevented the decrease of these channels in the Li-pilocarpine model of epilepsy. Figure 8 summarizes the possible changes that occur in astroglial proteins in the model of epilepsy at 56 days after pilocarpine administration, as well as the prevention of such changes by dexamethasone administration. Notice that elevated extracellular levels of $\mathrm{K}^{+}$decrease S100B secretion under basal conditions [60]. The mechanism involved in this effect is unclear at moment, but such an effect is not observed in the hippocampal slices from animals treated with pilocarpine. However, dexamethasone was able to reduce S100B secretion in the hippocampal slices from and epileptic rats in vitro. Moreover, our data allow us to speculate (but not affirm) that the protection provided by dexamethasone in this model could be useful against other epileptogenic agents such as traumatic

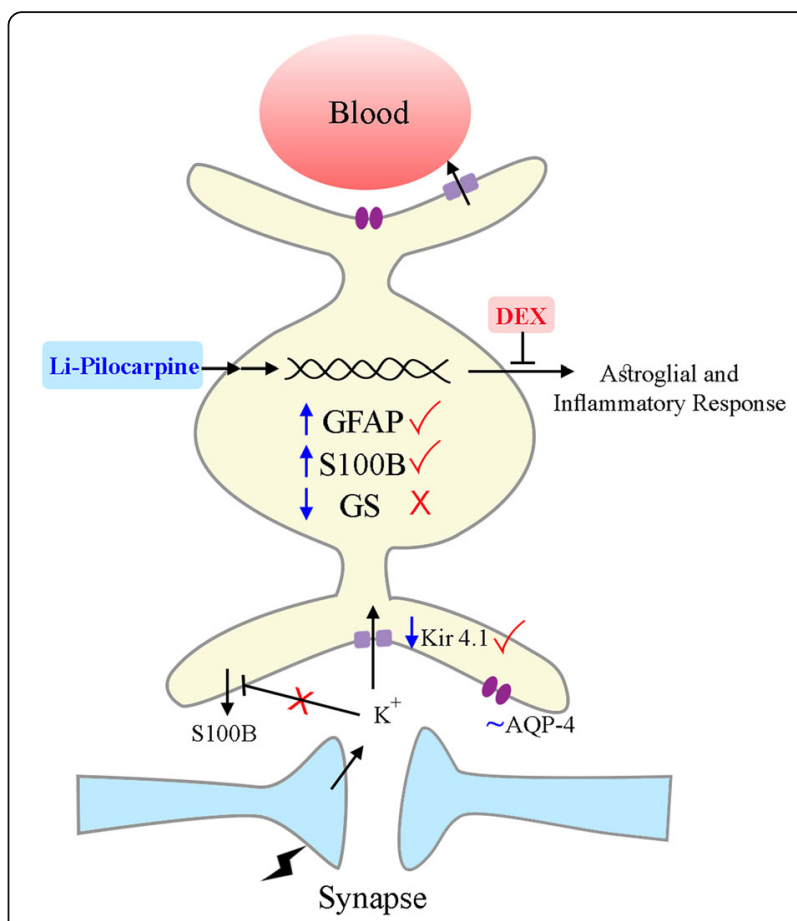

Fig. 8 Schematic representation of astroglial alterations induced by Li-pilocarpine (at 56 days) and prevented by dexamethasone. We postulate that the Li-pilocarpine insult causes an inflammatory and astroglial injury. Dexamethasone (administered $24 \mathrm{~h}$ after pilocarpine) was able to prevent such alterations partially. Neuronal activity released $\mathrm{K}^{+}$, which is buffered by astroglial activity. GFAP, S100B, and GS expressions are sensitive to dexamethasone. The reduction in $\mathrm{S} 100 \mathrm{~B}$ secretion in the high- $\mathrm{K}^{+}$medium was not observed in the hippocampal slices from Li-pilocarpine-treated animals. , $\uparrow$, and $\downarrow$ signify unchanged, increased, and decreased, respectively, caused by Li-pilocarpine administration; $\sqrt{ }$ and $X$ refer to the prevention or non-prevention, respectively, by dexamethasone (DEX)

brain injury or ischemia, in which neuroinflammation is present.

Some limitations of this study should be highlighted. Firstly, EEG records at different times would be useful to characterize SE and seizure activities later on. The absence of this data occurred in an effort to avoid surgery and the activation of neuroinflammation and astrogliosis by the lesion incurred by the introduction of electrodes. However, epileptic behavior analysis could provide valid evidence to suggest a protective role of dexamethasone in this model of epilepsy [84, 85]. Secondly, the different time points of 1,14 , and 56 days correspond to acute, latent (silent), and chronic epileptic phases, as determined in a previous study [49]. We did not perform a 14-day group in the second set of experiments to reduce the number of animals used in this study. Thirdly, this study demonstrates that dexamethasone administration $(10 \mathrm{mg} / \mathrm{kg}, 24$ and $36 \mathrm{~h}$ after SE) has clear neurochemical effects on the acute and chronic phases of Li-pilocarpine model of epilepsy. However, other protocols would be useful to delimit the best 
"window" and dose for steroid protection in this epilepsy model. Finally, dexamethasone prevented astroglial and inflammatory changes but did not alter the analyzed epileptic behavior, at least, between 7 and 25 days after SE induction, and therefore we cannot rule out the possibility that observed glial alterations constitute an epiphenomenon.

\section{Conclusions}

Our results indicate a decrease in neuroinflammation, astrogliosis, and astroglial dysfunction in the hippocampi of young rats submitted to the Li-pilocarpine model of epilepsy, at 1 and 56 days after intraperitoneal dexamethasone administration. In the acute hippocampal slices prepared at 1, 14, and 56 days after SE induction, basal S100B secretion and S100B secretion in high- $\mathrm{K}^{+}$ medium were not different at 1 and 56 days, in contrast to sham animals in which high- $\mathrm{K}^{+}$medium induced a decrease in S100B secretion. The addition of dexamethasone to the incubation medium per se induced a decrease in S100B secretion in sham and epileptic rats (1 and 56 days after SE induction). In the second set of experiments, we evaluated the in vivo effect of dexamethasone on hippocampal astroglial parameters ( 1 day after pilocarpine) in the epileptic model, at 2 and 56 days after SE. In addition to the improvement in inflammatory status (based on cytokine and PGE2 levels), dexamethasone prevented astrogliosis (based on GFAP and S100B content) and partially diminished astroglial dysfunction (based on Kir 4.1 protein and GSH content). The decrease in GS was not abrogated by dexamethasone, and AQP-4 was not altered in this epileptic model. All these parameters, with the exception of AQP-4, were altered, emphasizing the importance of this model for understanding alterations and mechanisms of epileptic disorders. In vivo dexamethasone administration, $24 \mathrm{~h}$ after SE induction, prevented most of the parameters analyzed, reinforcing the importance of anti-inflammatory steroid therapy in the Li-pilocarpine model and possibly in other epileptic conditions where neuroinflammation is present. Our data demonstrate specific alterations in astrocytes in this model and clearly contribute to the understanding of the importance of these cells in the pathogenesis of epilepsy, as well as suggest potential therapeutic targets for AED.

\section{Additional files}

Additional file 1: Figure studies. Schematic experimental design. Schematic experimental design of the two studies. The first set of experiments analyze S100B secretion in an ex vivo model of hippocampal slices of rats, from sham and SE animals at 1, 14, and 56 days after pilocarpine injection. Hippocampal slices were incubated in high- $\mathrm{K}^{+}$medium and dexamethasone. The second set of experiments evaluates dexamethasone treatment at 24 and $36 \mathrm{~h}$ after SE induction, in vivo at 1 and 56 days after dexamethasone injection. (TIFF 29 kb)

Additional file 2: Table S1. Behavior resumed. Epilepsy behavioral evaluation of SE animals. Evaluation of the occurrence of spontaneous epileptic seizures in animals submitted to the epilepsy model by Li-pilocarpine administration. Dexamethasone did not prevent behavioral changes. *All animals developed a spontaneous epileptic seizure and jumping and running behavior. (TIFF $16 \mathrm{~kb}$ )

\section{Abbreviations}

AQP-4: Aquaporin channel 4; COX1: Cyclooxygenase 1; COX2: Cyclooxygenase 2; CSF: Cerebrospinal fluid; GFAP: Glial fibrillary acid protein; GS: Glutamine synthetase; GSH: Reduced glutathione; IL-10: Interleukin-10; IL-1ß: Interleukin-1ß; Kir 4.1: Inwardly rectifying potassium channel 4.1; LDH: Lactate dehydrogenase; PGE2: Prostaglandin E2; SE: Status epilepticus; TNF-a: Tumor necrosis factor-a

\section{Acknowledgements}

The authors would like to thank the undergraduate student, Juliana Furtado, for the help with laboratory analyses.

\section{Funding}

This study was supported by the National Council for Scientific and Technological Development (CNPq, Brazil), Ministry of Education (MEC) CAPES, Brazil), State Foundation for Scientific Research of Rio Grande do Sul (FAPERGS), National Institute of Science and Technology for Excitotoxicity and Neuroprotection (MCT/INCTEN), and project CNPq 27/2014 -

Neurodegenerative diseases.

\section{Availability of data and materials}

All data generated or analyzed during this study are included in this published article.

\section{Authors' contributions}

AFKV organized and conducted all studies. FH, EN, and MCL helped with the animal experimentation. DLO and CAG aided in the discussion of data and writing the manuscript. All authors have read and approved of the final manuscript.

\section{Ethics approval}

The study was approved by the Committee of Animal Use of the Federal University of Rio Grande do Sul (project number 24472), and the animal procedures were in accordance with National Institute of Health Guide for the Care and Use of Laboratory Animals (NIH Publications No. 80-23).

\section{Consent for publication}

Not applicable.

\section{Competing interests}

The authors declare that they have no competing interests.

\section{Publisher's Note}

Springer Nature remains neutral with regard to jurisdictional claims in published maps and institutional affiliations.

Received: 15 November 2017 Accepted: 28 February 2018 Published online: 05 March 2018

\footnotetext{
References

1. Banerjee PN, Filippi D, Allen Hauser W. The descriptive epidemiology of epilepsy_a review. Epilepsy Res. 2009;85:31-45.

2. Dichter MA. Emerging insights into mechanisms of epilepsy: implications for new antiepileptic drug development. Epilepsia. 1994;35(Suppl 4):S51-7.

3. Dalby NO, Mody I. The process of epileptogenesis: a pathophysiological approach. Curr Opin Neurol. 2001;14:187-92.

4. Sander JW. The epidemiology of epilepsy revisited. Curr Opin Neurobiol. 2003;16:165-70.

5. Engel Jr J. Introduction to temporal lobe epilepsy. Epilepsy Res. 1996;26: 141-50.
} 
6. Téllez-Zenteno J, Hernánde-Ronquillo L. A review of the epidemiology of temporal lobe epilepsy. Epilepsy Res Treat. 2012;2012:630853. https://doi. org/10.1155/2012/630853.

7. Leite JP, Garcia-cairasco N, Ca EA. New insights from the use of pilocarpine and kainate models. Epilepsy Res. 2002;50:93-103.

8. Wahab A, Albus K, Gabriel S, Heinemann U. In search of models of pharmacoresistant epilepsy. Epilepsia. 2010;51:154-9.

9. Cavalheiro EA, Leite JP, Bortolotto ZA, Turski WA, Ikonomidou C, Turski L. Long-term effects of pilocarpine in rats: structural damage of the brain triggers kindling and spontaneous recurrent seizures. Epilepsia. 1991;32:778-82.

10. Goffin K, Nissinen J, Van Laere K, Pitkänen A. Cyclicity of spontaneous recurrent seizures in pilocarpine model of temporal lobe epilepsy in rat. Exp Neurol. 2007;205:501-5.

11. Chakir A, Fabene PF, Ouazzani R, Bentivoglio M. Drug resistance and hippocampal damage after delayed treatment of pilocarpine-induced epilepsy in the rat. Brain Res Bull. 2006;71:127-38.

12. Arisi GM, Ruch M, Foresti ML, Mukherjee S, Ribak CE. Astrocyte alterations in the hippocampus following pilocarpine-induced seizures in aged rats. Aging Dis. 2011;2(4):294-300.

13. Borges K. Neuronal and glial pathological changes during epileptogenesis in the mouse pilocarpine model. Exp Neurol. 2003;182:21-34.

14. de Oliveira DL, Fischer A, Jorge RS, da Silva MC, Leite M, Gonçalves CA, et al. Effects of early-life LiCl-pilocarpine-induced status epilepticus on memory and anxiety in adult rats are associated with mossy fiber sprouting and elevated CSF S100B protein. Epilepsia. 2008;49:842-52.

15. Shapiro LA, Wang L, Ribak CE. Rapid astrocyte and microglial activation following pilocarpine-induced seizures in rats. Epilepsia. 2008:49:33-41.

16. Yang F, Liu Z, Chen J, Zhang S. Roles of astrocytes and microglia in seizureinduced aberrant neurogenesis in the hippocampus of adult rats. J Neurosci Res. 2010;88(3):519-29.

17. De Lanerolle NC, Lee T, Spencer DD. Astrocytes and epilepsy. Neurotherapeutics. 2010;7:424-38.

18. Foresti ML, Arisi GM, Shapiro LA. Role of glia in epilepsy-associated neuropathology, neuroinflammation and neurogenesis. Brain Res Rev Elsevier BV. 2010;66:115-22.

19. Perea G, Navarrete M, Araque A. Tripartite synapses: astrocytes process and control synaptic information. Trends Neurosci. 2009;32:421-31.

20. Coulter DA, Steinhauser C. Role of astrocytes in epilepsy. Cold Spring Harb Perspect Med. 2015;5:1-12

21. Seifert G, Steinhäuser C. Neuron-astrocyte signaling and epilepsy. Exp Neurol Elsevier BV. 2011;244:4-10.

22. Tian G, Azmi H, Takano T, Xu Q, Peng W, Lin J, et al. An astrocytic basis of epilepsy. Nat Med. 2005;11(9):973-81.

23. Bedner P. Astrocyte uncoupling as a cause of human temporal lobe epilepsy. Brain. 2015;138:1208-22.

24. Robel S, Buckingham SC, Boni JL, Campbell SL, Danbolt NC, Riedemann T, et al. Reactive astrogliosis causes the development of spontaneous seizures. J Neurosci. 2015;3:3330-45.

25. Marchi N, Granata T, Janigro D. Inflammatory pathways of seizure disorders. Trends Neurosci. 2014;37:55-65.

26. De Simoni MG, Perego C, Ravizza T, Moneta D, Conti M, Marchesi F, et al. Inflammatory cytokines and related genes are induced in the rat hippocampus by limbic status epilepticus. Eur J Neurosci. 2000;12:2623-33.

27. Ravizza T, Rizzi M, Perego C, Richichi C, Vel J, Mosh SL, et al. Inflammatory response and glia activation in developing rat hippocampus after status epilepticus. Epilepsia. 2005;46:113-7.

28. Rizzi M, Perego C, Aliprandi M, Richichi C, Ravizza T, Colella D, et al. Glia activation and cytokine increase in rat hippocampus by kainic acid-induced status epilepticus during postnatal development. Neurobiol Dis. 2003;14: 494-503.

29. Somera-Molina KC, Robin B, Somera CA, Anderson C, Stine C, Koh S, et al. Glial activation links early-life seizures and long-term neurologic dysfunction: evidence using a small molecule inhibitor of proinflammatory cytokine upregulation. Epilepsia. 2007;48:1785-800.

30. Devinsky O, Vezzani A, Najjar S, De Lanerolle NC, Rogawski MA. Glia and epilepsy: excitability and inflammation. Trends Neurosci. 2013;36:174-84.

31. Portela L, Tort A, Walz R, Bianchin M, Trevisol-Bittencourt P, Wille P, et al. Interictal serum S100B levels in chronic neurocysticercosis and idiopathic epilepsy. Acta Neurol Scand. 2003;108:424-7.

32. Chen W, Tan Y, Ge Y. The effects of Levetiracetam on cerebrospinal fluid and plasma NPY and GAL, and on the components of stress response system, hs-CRP, and S100B protein in serum of patients with refractory epilepsy. Cell Biochem Biophys. 2015;73:489-94.

33. Sorci G, Giovannini G, Riuzzi F, Bonifazi P, Zelante T, Bistoni F, et al. The danger signal S100B integrates pathogen-and danger-sensing pathways to restrain inflammation. PLoS Pathog. 2011;7:e1001315.

34. Guerra MC, Tortorelli LS, Galland F, Da Ré C, Negri E, Engelke DS, et al. Lipopolysaccharide modulates astrocytic S100B secretion: a study in cerebrospinal fluid and astrocyte cultures from rats. J Neuroinflammation. 2011;8:128.

35. Leite MC, Galland F, De Souza DF, Guerra MC, Bobermin L, Biasibetti R, et al. Gap junction inhibitors modulate S100B secretion in astrocyte cultures and acute hippocampal slices gap junction inhibitors modulate S100B secretion in astrocyte cultures and acute hippocampal slices. J Neurosci Res. 2009:87: 2439-46.

36. Niu H, Hinkle DA, Wise PM. Dexamethasone regulates basic fibroblast growth factor, nerve growth factor and $\mathrm{S100}$ beta expression in cultured hippocampal astrocytes. Brain Res Mol Brain Res. 1997:51:97-105.

37. Gonçalves CA, Concli Leite M, Nardin P. Biological and methodological features of the measurement of $\mathrm{S100B}$, a putative marker of brain injury. Clin Biochem. 2008;41:755-63.

38. Donato R, Sorci G, Riuzzi F, Arcuri C, Bianchi R, Brozzi F, et al. S100B's double life: intracellular regulator and extracellular signal. Biochim Biophys Acta. 2009;1793(6):1008-22

39. Yoshikawa M, Suzumura A, Tamaru T, Takayanagi T, Sawada M. Effects of phosphodiesterase inhibitors on cytokine productio $n$ by microglia. Mult Scler. 1999:5:126-33.

40. Chen J, Cai F, Jiang L, Hu Y, Feng C. A prospective study of dexamethasone therapy in refractory epileptic encephalopathy with continuous spike-andwave during sleep. Epilepsy Behav. 2016;55:1-5.

41. Haberlandt E, Weger C, Sigl SB, Rosta K, Rauchenzauner M, Scholl-bu S, et al. Adrenocorticotropic hormone versus pulsatile dexamethasone in the treatment of infantile epilepsy syndromes. Pediatr Neurol. 2010:42(1):21-7.

42. Al-Shorbagy MY, El Sayeh BM, Abdallah DM. Diverse effects of variant doses of dexamethasone in lithium-pilocarpine induced seizures in rats. Can J Physiol Pharmacol. 2012;90:13-21.

43. Duffy BA, Chun KP, Ma D, Lythgoe MF, Scott RC. Dexamethasone exacerbates cerebral edema and brain injury following lithium-pilocarpine induced status epilepticus. Neurobiol Dis. 2014;63:229-36.

44. Curia G, Longo D, Biagini G, Jones RSG, Avoli M. The pilocarpine model of temporal lobe epilepsy. J Neurosci Methods. 2008;172:143-57.

45. Andersen SL. Changes in the second messenger cyclic AMP during development may underlie motoric symptoms in attention deficit/ hyperactivity disorder (ADHD). Behav Brain Res. 2002;130:197-201.

46. Engelhardt B. Development of the blood-brain barrier. Cell Tissue Res. 2003; 314:119-29.

47. Nehlig A, De Vasconcelos AP, Boyet S. Postnatal changes in local cerebral blood flow measured by the quantitative autoradiographic [14C] iodoantipyrine technique in freely moving rats. J Cereb Blood Flow Metab. 1989;9:579-88

48. Ben-Ari Y. Excitatory actions of GABA during development: the nature of the nurture. Nat Rev Neurosci. 2002;3:728-39.

49. Vizuete AFK, Mittmann MH, Gonçalves CA, De Oliveira DL. Phase-dependent Astroglial alterations in Li-pilocarpine- induced status epilepticus in young rats. Neurochem Res. 2017;42:2730-42.

50. Allen S, Shea JM, Felmet T, Gadra J, Dehn PF. A kinetic microassay for glutathione in cells plated on 96-well microtiter plates. Methods Cell Sci. 2000;22:305-12.

51. Leite MC, Galland F, Brolese G, Guerra MC, Bortolotto JW, Freitas R, et al. A simple, sensitive and widely applicable ELISA for S100B: methodological features of the measurement of this glial protein. J Neurosci Methods. 2008; 169:93-9.

52. Tramontina F, Leite MC, Cereser K, de Souza DF, Tramontina AC, Nardin P, et al. Immunoassay for glial fibrillary acidic protein: antigen recognition is affected by its phosphorylation state. J Neurosci Methods. 2007;162:282-6.

53. Minet R, Villie F, Marcollet M, Meynial-Denis D, Cynober L. Measurement of glutamine synthetase activity in rat muscle by a colorimetric assay. Clin Chim Acta. 1997;268:121-32

54. Peterson GL. A simplification of the protein assay method of Lowry et al. which is more generally applicable. Anal Biochem. 1977;83:346-56.

55. Rogawski MA. Diverse mechanisms of antiepileptic drugs in the development pipeline. Epilepsy Res. 2006;69:273-94. 
56. Sun C, Mtchedlishvili Z, Erisir A, Kapur J. Diminished neurosteroid sensitivity of synaptic inhibition and altered location of the a4 subunit of GABA a receptors in an animal model of epilepsy. J Neurosci. 2007;27:12641-50.

57. Joshi S, Rajasekaran K, Kapur J. GABAergic transmission in temporal lobe epilepsy: the role of neurosteroids. Exp Neurol. 2013;244:36-42.

58. Ramey WL, Martirosyan NL, Lieu CM, Hasham HA, Lemole GM, Weinand ME. Current management and surgical outcomes of medically intractable epilepsy. Clin Neurol Neurosurg. 2013;115:2411-8.

59. Vezzani A, Lang B, Aronica E. Immunity and inflammation in epilepsy. Cold Spring Harb Perspect Med. 2015;6:a022699.

60. Nardin P, Tortorelli L, Quincozes-Santos A, De Almeida LMV, Leite MC, Thomazi AP, et al. S100B secretion in acute brain slices: modulation by extracellular levels of Ca2+ and K+. Neurochem Res. 2009;34:1603-11.

61. Zanotto C, Abib RT, Batassini C, Tortorelli LS, Biasibetti R, Rodrigues L, et al. Non-specific inhibitors of aquaporin-4 stimulate S100B secretion in acute hippocampal slices of rats. Brain Res. 2013;1491:14-22.

62. Butt AM, Kalsi A. Inwardly rectifying potassium channels (Kir) in central nervous system glia: a special role for Kir4.1 in glial functions. J Cell Mol Med. 2006;10:33-44.

63. Strohschein S, Uttmann KH, Gabriel S, Binder DK. Impact of Aquaporin-4 channels on $\mathrm{K} 1$ buffering and gap junction coupling in the hippocampus. Glia. 2011;980:973-80.

64. Duport S, Stoppini L, Corrèges P. Electophysiological approach of theantiepileptic effect of dexamethasone on hippocampal slice culture using a multirecord system: the physiocard. Life Sci. 1997;60:251-6.

65. Avola R, Di Tullio MA, Fisichella A, Tayebati SK, Tomassoni D. Glial fibrillary acidic protein and vimentin expression is regulated by glucocorticoids and neurotrophic factors in primary rat astroglial cultures. Clin Exp Hypertens. 2004;26:323-33.

66. Bruccoleri A, Pennypacker KR, Harry GJ. Effect of dexamethasone on elevated cytokine mRNA levels in chemical-induced hippocampal injury. J Neurosci Res. 1999:57:916-26.

67. Jaquins-Gerstl A, Shu Z, Zhang J, Liu Y, Weber SG, Michael AC. The effect of dexamethasone on gliosis, ischemia, and dopamine extraction during microdialysis sampling in brain tissue. Anal Chem. 2011;83:7662-7.

68. Kleindienst A, Meissner S, Eyupoglu IY, Parsch H, Schmidt CBM. Dynamics of $\mathrm{S} 100 \mathrm{~B}$ release into serum and cerebrospinal fluid following acute brain injury. Acta Neurochir Suppl. 2010;106:247-50.

69. Gonçalves CA, Leite MC, Guerra MC. Adipocytes as an important source of serum S100B and possible roles of this protein in adipose tissue. Cardiovasc Psychiatry Neurol. 2010;2010:790431. https://doi.org/10.1155/2010/790431.

70. Marchi N, Granata T, Freri E, Ciusani E, Ragona F, Puvenna V, et al. Efficacy of anti-inflammatory therapy in a model of acute seizures and in a population of pediatric drug resistant epileptics. PLoS One. 2011;6:e18200.

71. Eid T, Behar K, Dhaher R, Bumanglag AV, T-SW L. Roles of glutamine synthetase inhibition in epilepsy. Neurochem Res. 2012;37:2339-50.

72. Van Der W, Hessel E, Bos I, Mulder S, Verlinde S, Van Eijsden P, et al Persistent reduction of hippocampal glutamine synthetase expression after status epilepticus in immature rats. Eur J Neurosci. 2014;40:3711-9.

73. Patel AJ, Hunt A, Tahourdin CSM. Regulation of in vivo glutamine synthetase activity by glucocorticoids in the developing rat brain. Dev Brain Res. 1983;10:83-91.

74. Huang TL, Banion KO. Interleukin-1B and tumor necrosis factor-a suppress dexamethasone induction of glutamine synthetase in primary mouse astrocytes. J Neurochem. 1998:71:1436-42.

75. Freitas RM, Fonteles MMF. Oxidative stress in the hippocampus after pilocarpine- induced status epilepticus in Wistar rats. FEBS J. 2005;272: 1307-12.

76. Waldbaum S, Patel M. Mitochondria, oxidative stress, and temporal lobe epilepsy. Epilepsy Res. 2010;88:23-45.

77. Hong S, Xin Y, Haiqin W, Guilian Z. The PPAR agonist rosiglitazone prevents cognitive impairment by inhibiting astrocyte activation and oxidative stress following pilocarpine-induced status epilepticus. Neurol Sci. 2012;33:559-66.

78. Nagao Y, Harada Y, Mukai T, Shimizu S, Okuda A, Fujimoto M, et al. Expressional analysis of the astrocytic Kir 4.1 channel in a pilocarpineinduced temporal lobe epilepsy model. Front Cell Neurosci. 2013;7:1-10,

79. Zhao M, Bousquet E, Valamanesh F, Farman N. Differential regulations of AQP4 and Kir 4.1 by triamcinolone acetonide and dexamethasone in the healthy and inflamed retina. Invest Ophthalmol Vis Sci. 2011;52:6340-7.

80. Fazekas I, Szakács R, Mihály A, Zádor Z, Krisztin-Péva B, Juhász A, et al. Alterations of seizure-induced c- fos immunolabelling and gene expression in the rat cerebral cortex following dexamethasone treatment. Acta Histochem. 2006;108:463-73.

81. Pieretti S, Di Giannuario A, Loizzo A, Sagratella S, Scotti de Carolis A, Capasso A, et al. Dexamethasone prevents epileptiform activity induced by morphine in in vivo and in vitro experiments. J Pharmacol Exp Ther. 1992; 263:830-9.

82. Rojas A, Jiang J, Ganesh T, Yang M, Lelutiu N, Dingledine R. Cyclooxygenase-2 in epilepsy. Epilepsia. 2014;55:17-25.

83. Laping NJ, Teter B, Nichols NR, Rozovsky I, Finch CE. Glial fibrillary acidic protein: regulation by hormones, cytokines, and growth factors. Brain Pathol. 1994:1:259-75.

84. Kim J-E, Ryu HJ, Choi SY, Kang T-C. Tumor necrosis factor-a-mediated threonine 435 phosphorylation of p65 nuclear factor-kB subunit in endothelial cells induces vasogenic edema and neutrophil infiltration in the rat piriform cortex following status epilepticus. J Neuroinflammation. 2012;9:1-13.

85. Hung Y-W, Lai M-T, Tseng Y-J, Chou C-C, Lin Y-Y. Monocyte chemoattractant protein-1 affects migration of hippocampal neural progenitors following status epilepticus in rats. J Neuroinflammation. 2013; $10: 1-11$

\section{Submit your next manuscript to BioMed Central and we will help you at every step:}

- We accept pre-submission inquiries

- Our selector tool helps you to find the most relevant journal

- We provide round the clock customer support

- Convenient online submission

- Thorough peer review

- Inclusion in PubMed and all major indexing services

- Maximum visibility for your research

Submit your manuscript at www.biomedcentral.com/submit
) Biomed Central 